\title{
Fostering multilingual competence in the EFL classroom
}

\author{
Susan Abney \\ Vista Heights Middle School in Utah \\ Anna Krulatz \\ Sør-Trøndelag University College
}

\begin{abstract}
As classrooms around Europe are becoming increasingly more linguistically and culturally diverse, teachers need to adapt their teaching to accommodate minority languages students. While developing their proficiency in the language of the target community, these students almost invariably receive instruction in English as a foreign language (EFL). Recognizing the important role EFL teachers play in the overall cognitive and linguistic development of minority students, this paper discusses the following pedagogical practices for the $21^{\text {st }}$ century, diverse EFL classrooms: welcoming diversity, multimodality of input, funds of knowledge, clear goals, opportunities for interaction, integrating language with compelling content, facilitating multi-literacy, and differentiating instruction and assessment. By providing both theoretical support and practical tips, the paper aims to empower EFL teachers to foster linguistically and culturally rich environments and support their students' multilingual development.
\end{abstract}

\section{Introduction}

Third language acquisition and trilingual educational contexts are becoming a norm rather than an exception (Cenoz et al., 2001). With the increased international mobility, a classroom in which all students share the same mother tongue and cultural background is no longer a reality. Schools all around Europe have seen a rapid increase in their immigrant student populations and have to provide language support systems including language specialists who can oversee the development of the target language (e.g. Swedish in Sweden, Norwegian in Norway) and provide support for the maintenance of the home language. At the same time, the role of English as a lingua franca often means that the students in non-English speaking countries are consecutively developing a competence in a third, foreign language. However, with the exception of the schools following the Content and Language Integrated Learning (CLIL) model, e.g. the schools in the European School network (Beatens Beardsmore, 1979, 1980; Baker 1996), English language instruction is often perceived as separate from the instruction in the official language of the school and the minority language of the student. At the same time, the Council of Europe has deemed both multilingualism and foreign language teaching as highly important, and recognized the crucial role foreign language teachers play in supporting multilingualism in the schools (Council of Europe, 2005).

2. In the classroom

Rooted in the belief that multilingualism should be viewed as an asset rather than a hindrance, this paper aims to empower English as foreign language (EFL) teachers to foster their students' multilingual competence. It discusses the following eight pedagogical 
practices: welcoming diversity, funds of knowledge, clear goals, multimodality of input, opportunities for interaction, integrating language instruction with compelling content, facilitating multi-literacy, and differentiating instruction and assessment. Even though we agree with those researchers who argue that acquisition of a third language is more complex than second language acquisition (Jessner, 2006, p 14), we believe that results from research on second language acquisition (SLA) make important implications for teaching EFL to multilingual students. Therefore, the teaching practices presented here stem from both research on SLA and bilingualism as well as multilingualism. A theoretical backing and a guide for classroom implementation are provided for each of the practices and the Common European Framework for Languages (CERF) is used as an indicator to help teachers choose activities and strategies most suitable for their students. While we realize that all classrooms are unique, and that it is ultimately the teacher who selects the methods and approaches that are the most appropriate, we hope that this paper will provide EFL teachers around Europe with some ideas that will help them in their work with minority language students.

\subsection{Welcoming linguistic and cultural diversity}

Minority language students bring with them rich experiences, and cultural and linguistic knowledge that not only do not hinder their further cognitive and linguistic development in the target language and English as a foreign language, but that can be explored to create linguistically and culturally rich classroom environments. According to Cummins et al. (2005), minority language students' academic engagement actually depends on "the extent [to which] instruction affirms their identities and enables them to invest their identities in learning" ( $p$ 40). As language teachers and language models, EFL teachers have a special role in welcoming the students' linguistic and cultural diversity and thus creating a rich learning environment for all students in the classroom.

Coelho (2004) suggests several strategies, such as class photographs, questionnaires and language surveys, inclusive displays, and peer tutors and partners that can be implemented to welcome and integrate minority language students into the classroom community. These strategies can be used with students of all proficiency levels, but are specifically aimed at students with lower proficiency levels (A1-B1) as it is assumed that students can rely on their home languages. As these activities include both minority and majority students, they contribute to the increased language and cultural awareness of all students in the classroom. For example, the teacher can take and display (with parents' permission) photographs of every student in the class, and also encourage students to write short bios either in English or in their home language, or both. The displays can be expanded and improved over time, which also provides a forum where the newcomers can demonstrate their increasing language proficiency ( $\mathrm{p} 38$ ). Questionnaires and language surveys can be used to promote awareness about linguistic and cultural diversity in the classroom and in the community. More advanced students (B1-C1) can become researchers by collecting and visually displaying linguistic and cultural data, which also creates opportunities for making cross-curricular links other content areas, e.g. mathematics (p 39).

In addition to these practices, EFL teachers can also hold school gatherings for students and families, celebrating student success in academic or citizenship achievement. This gives families a way to become more familiar with the school and the educators in a more relaxed setting. Also, EFL teachers can have gatherings where each student and family brings a dish from his or her own home country. By participating in such extra-curricular activities, students can gain an appreciation for the other students' backgrounds in the class. Families are much more at ease with the casual atmosphere and are less intimidated by an unfamiliar school system. EFL teachers can also have students share translations of different simple texts in the classroom with their fellow students. Students love to hear what other 
languages sound like, and other students' simple words and phrases are an excellent way to bridge the different language backgrounds in the classroom. A simple, "How do you say this in__?" is an easy way to incorporate students' linguistic backgrounds without much effort on the educator's part. Similarly, teachers and students can greet each other using different languages spoken in the classroom including the main language of the school and English as lingua franca (López-Gopar et al., 2014).

Class awards for various achievements in class, such as, "Most Improved on Verb Tenses" written in a student's L1 is another excellent way to celebrate diverse linguistic backgrounds. The parents of the student can read the award and feel a deeper investment in the success of their child. Awards can be very simple, printed on cardstock, and using any word-processing program. Another activity is to play BINGO, incorporating all of the students' native languages for any simple English word group such as, "articles of clothing" on the BINGO card. Students can also make up simple card games to be used in class, such as GO FISH using native language words for other categories such as household items, what is found in a bedroom, what is used in the kitchen and other day-to-day phrases and words.

\subsection{Funds of knowledge}

Funds of knowledge refers to "historically accumulated and culturally developed bodies of knowledge and skills essential for household or individual functioning and wellbeing" (Gonzalez et al. 2005, p 72). EFL teachers can draw on their minority students' cultural experiences and knowledge of areas such as farming, religion, household economics, childcare, and geography and religion of the home country to benefit the whole classroom community, including the domestic students and the teachers. Examples of activities include cooperative learning in small groups to share ideas and texts from students' diverse backgrounds, and playing in-class games from each of the students' cultural backgrounds. In addition, students can write letters about their home cultures to one another in English. Books both in English and in native languages of the students should be available in the classroom and to take home. Teachers can assign the same book to the whole class, but allow each student to read the book in his or her L1 if they do not feel competent enough to read it in English. However, class discussions should be conducted in English. Activities that focus on each student's home country are also useful. Each student has something to offer the class regardless of where he or she comes from. These activities are appropriate for all proficiency levels (A1-C2), and can be easily modified through appropriate scaffolding.

To best utilize students' funds of knowledge, teachers should research and become familiar with the issues faced by his or her students in class. That understanding should be the foundation on which all funds of knowledge activities are based. By drawing on students' background knowledge, integrating relevant topics, and making cross-cultural links, teachers optimize deeper understanding and development of higher order thinking skills. They also enable students to be in charge of their own learning (Cummins et al. 2005, p 38) while at the same time promoting the use of English as a means of meaningful communication rather than just an object of study.

\subsection{Clear goals}

Regardless of the students' level of proficiency, every EFL lesson should be guided by clear and measurable goals. While minority language students should attain the same advanced goals that are stated for the majority students, to sustain student motivation, it is important that the goals and expectations be attainable. Teacher guides and curricula, for example LK06 in Norway (Utdanningsdirektoratet, 2006), often contain goals that are broad or difficult for students to understand. For this reason, Echevarría et al. (2008) suggest that teachers rephrase the objectives "[using] student-friendly language that suits the age and 
proficiency levels of the class" (p 24). For example, instead of saying, "Students will analyze the influence of inventions on modern society and will document findings through writing," teachers should say, "By the end of the lesson, you will be able to review your current ideas about inventions through watching a film about inventions and filling out a graphic organizer." In addition, it is important to include a wide variety of language objectives. As Lindahl and Watkins (2014) caution, many teachers find writing language objectives challenging and often focus exclusively on vocabulary while ignoring other aspects of language ( $p$ 197). To address this gap, the authors propose 'a language objective menu' that consists of six language areas: reading comprehension (e.g. using contextual clues), vocabulary (e.g. basic oral vocabulary), word study (e.g. homophones, prefixes), functional language (e.g. comparing/contrasting), grammar (e.g. subject-verb agreement) and writing and conventions (e.g. genre awareness). By carefully considering the language demands needed for a given task, balancing the language demands in each lesson and selecting appropriate strategies, teachers can promote successful EFL instruction. Teachers also need to make sure their objectives are clearly posted for the students to see, perhaps using some type of a checklist for the weekly objectives to see if students feel they have met them. Clear objectives posted in the room for the whole unit are also helpful.

\subsection{Multimodality of input}

EFL teachers working with minority language students need to navigate between multiple languages present in the classroom: the majority language spoken in the community, English as a lingua franca, and the respective languages of all the minority students in the school. Minority language students constitute a very heterogeneous group and their English language proficiency may vary depending on several factors such as the amount and type of English instruction they received in their home country and the age of arrival in the target country. For these reasons, regardless of the level of proficiency, enhancing the comprehensibility of the English input through the engagement of various modalities is of utmost importance. Comprehensible input is a necessary condition for language acquisition to happen (Cummins, 2001; Krashen, 1982, 2003). Oral input can be adapted by using a slower rate of speech, clear enunciation, and increased wait time for responses. Written input can be modified by simplifying sentence structure, highlighting key words, and defining new terms. However, we would also like to argue that minority language students can benefit from a wide range of modalities in which the input is provided. This includes using gestures and visuals, but also enabling access to both printed and online resources. For example, before beginning a new lesson, the teacher can print the PowerPoint slides for the student to assist him or her in taking notes. Another strategy is to provide bulleted lists instead of long pieces of text. Moreover, EFL teachers should try to have native language reading choices in the classroom, and give the text in L1 to the student before the English version is to be read in class.

Teachers also need to make sure all students know the key components of the lesson: Who, What, Where, When, Why. Online resources are nearly endless and teachers should take advantage of online programs and games to enhance English language learning. Finally, teachers can vary the length of time in which a student is required to finish an assignment.

Various language learning strategies should be taught to optimize the benefits of multilingualism. As Cenoz and Gorter (2014) point out, multilingual resources need to be activated because language users may not be aware that they have access to them, which is often observed in traditional instructional settings where different languages in multilingual repertoires are perceived as separate. One way to promote student awareness of the linguistic resources they have is to encourage students to find similarities in the native language, the main language of the school, and English such as cognates, close spelling and meanings. Students can also be assigned a "classwork buddy" to get assistance from another student. In 
addition, reading strategies can be promoted, and students can be encouraged to document their learning on some type of graphic organizer.

\subsection{Opportunities for interaction}

Many EFL classrooms are dominated by the teacher who assumes the role of a dispenser of knowledge. However, language acquisition scholars argue that student-to-student communication concerning the lesson concepts promotes language learning. This belief is expressed in the interaction hypothesis (Long, 1996). Echevarría et al. (2008) summarize the following benefits of interaction in the classroom: brain stimulation, increased motivation, reduced risk in comparison with a teacher-centered classroom where students are expected to answer immediately when called on, more processing time, and increased attention ( $\mathrm{p} \mathrm{116).}$ Creating opportunities for interaction in heterogeneous EFL classrooms may be challenging for the teacher because not all cultures value this way of teaching and some students may resist working in groups. However, if grouping configurations are carefully varied (i.e. individual work, pair work, small groups, large groups, whole class) and students are given some options, with sufficient time, both minority and majority students should gradually become more confident in working collaboratively with their peers.

Group work creates opportunities for learning that are absent from teacher-centered classrooms. For instance, paring lower level students with higher level students gives each student a chance to foster learning in the other. When a higher level student tutors or teaches a concept, the concept is reinforced. Students tend to listen to their peers much more than the instructor. Small groups also provide a way for students to express themselves without the pressure of having to present in front of an entire class, and confidence is built over time. Additionally, students are able to combine their knowledge to accomplish more difficult tasks. Normally, each group needs to have a group leader to direct the group. Specific written instructions and objectives should be given to the group leader, but if possible, the group leader position should be rotated between members. Complex assignments should be broken up into sections, and each group member should accomplish a given task. All group members should be held accountable through the use of an accountability chart and reflection. These strategies can be used with students of all proficiency levels.

\subsection{Integrating language instruction with compelling content}

In many EFL classrooms around the world, English language is still treated as an object of study rather than a means of meaningful communication and a tool that allows us to access the information we need. Krashen (2013) argues that language acquisition is optimized if it is supported through compelling content, i.e. materials that are so fascinating that students forget they are in the classroom learning a foreign language ( $p$ 15). Related to the compelling input hypothesis is the concept of extensive reading, also referred to as self-selected reading or free voluntary reading. It stipulates that students who are allowed to select their own reading materials based on their individual interests engage in reading for pleasure, which subsequently leads to accelerated language acquisition (Krashen, 2005). Every student, when appropriately stimulated, can surprise us with some unusual interest or interests. All that remains is to provide appropriate texts that explore those areas and topics. While all students can benefit from extensive reading to help them acquire a foreign language, it is particularly important for minority language students, who may come from low-literacy traditions, and for whom extensive reading can have a positive impact on their language acquisition, attainment of literacy skills and overall cognitive development.

EFL teachers can promote extensive reading in many ways. For example, they can create English classroom libraries that contain simplified and graded reading materials, designate specific times for reading, read aloud to students, and read at the same time their 
students are reading. In addition, students must have a choice in their reading material. Teachers should allow students to bring books from home and then share and reflect as to what prompted them to choose this particular book and what they have learned from it. Book talks are an excellent way to promote reading in the classroom. Students love to hear other students and the instructor discuss favorite books and why they chose to read them. Showing short films and documentaries with English subtitles is also a great way to promote literacy skills. Finally, teachers should allow students to read on their electronic devices, such as phones and iPads to enable students to take advantage of electronic books available at literally - their fingertips. Offering different types of adapted novels, e.g. graphic novels, is also an excellent way for students to understand difficult literature, such as Shakespeare plays.

\subsection{Facilitating multi-literacy}

Findings from research suggest that using the minority language in family, social, and educational settings has a positive impact on the acquisition of English as a third language (e.g., Lasagabaster, 1997 as quoted in Sagasta Errasti, 2003). In addition, several studies have concluded that a developed literacy in the first language positively impacts third language learning (e.g., Swain et al., 1990; Sagasta Errasti, 2003) and that using students' first language in the classroom can enhance their writing skills (Stille \& Cummins, 2013). Focus on Multilingualism, an approach to the study of multilingual development in educational contexts (Cenoz \& Gorter, 2014) is based in the idea that "all languages used by multilingual speakers and learners can act as connected growers" ( $p$ 246). Thus, to support the development of literacy skills in English, EFL teachers should draw on the full range of their students' language resources. Schwarzer et al. (2003) list numerous ideas to foster literacy, for example creating a multiliterate print environment in the classroom, using literature in students' native languages, and creating multiliterate projects. Stille and Cummins (2013) suggest explicitly encouraging students to use both English and their first language as a scaffold in literacy activities (p 633).

A specific example of fostering literacy through the first language in the EFL classroom is creating an in-class library of books from each of the students' native backgrounds. For more advanced students (B1-C2), books in English can be provided. Magazines from native countries are also a great resource. In addition, students can read about one another's cultures in English magazines from various English-speaking countries, and they can write poems, short stories, and biographies in their native languages with added English translations. If a student's literacy skills in both languages are sufficiently developed, these tasks can be performed individually, but both teacher and peer support should be exploited to support students with emerging or low literacy skills. Performing a reader's theatre is also an excellent option to promote student engagement and multiliteracy development. By allowing students to utilize the other languages that are available to them, EFL teachers can "[validate] linguistic repertoires and plurilingual identities" (Stille \& Cummins, 2013, p 634) and thus promote the development of literacy in English.

\subsection{Differentiating instruction and assessment}

In culturally and linguistically diverse classroom, one-size-fits-all instruction would privilege a narrow student audience. Successful EFL teachers working with minority language students need to recognize the heterogeneity of their classrooms and "provide multiple avenues of learning and differing challenges to a varied student population" (Levine \& McCloskey, 2013, p 68). Such teachers consider their students' different learning styles and proficiency levels, modify both the materials used and grouping configurations, and allow their students to make individual choices in demonstrating the attainment of learning goals. O'Malley and Valdez Pierce (1996) use the term 'authentic assessment' to refer to multiple 
forms of assessment that allow for differentiation, such as story-telling, writing samples and portfolios, projects and exhibitions, experiments, demonstrations, teacher observations, and student self-assessment.

Let us consider some more concrete examples of differentiated instruction and assessment. To begin, students can be grouped according to their English proficiency level, and both lessons and assessments can be modified to fit each student. Teachers should print PowerPoint Presentation slides for students of lower proficiency levels (A1-B1) who are not able to take notes as needed, as well as adjust the number of tasks and the cognitive demands of questions. At the same time, content should remain unchanged, i.e. all students should be learning the same concepts. Highlighted vocabulary with definitions is also a great way to differentiate instruction. In addition, students should self-reflect at the end of every lesson so that they can determine if they have mastered the objectives for the day.

Many EFL teachers rely on written assessment (e.g. sentence completion tasks or short compositions), but minority language students should be offered options. For example, some students may prefer to give an oral report instead of writing an essay. Some students enjoy making films or short documentaries, while others love to write short plays and have the class perform them. Yet others are artistic and can use that ability to convey learning through drawings and illustrating another student's work. Minority language students should be allowed to show learning through their various talents. Many students enjoy designing their own projects, especially when given explicit objectives to accomplish. Teachers should ask how students would like to show what they have learned and approve the means ahead of time.

\section{Conclusion}

Without doubt, $21^{\text {st }}$ century EFL teachers face challenges as cultural and linguistic diversities in their classrooms increase. Many may feel that they lack preparation to work with multilingual students because they have not received adequate pedagogical training. Others may be intimidated and discouraged by the fact that they do not speak the languages represented in the classroom, which it is often seen as a necessary condition for working with diverse student populations.

Lambert (1974) has proposed the notion of additive vs. subtractive bilingualism, prioritizing additive bilingualism which means that language learners develop their second language while at the same time maintaining and developing their mother tongue skills. As language role models, EFL teachers play an important role in the education of all students, and in particular the academic, linguistic and cognitive development of minority language students. The challenge is much more complex because in addition to supporting minority language students' mother tongue and the development of the target language, i.e. the language spoken by the target community, EFL teachers' role is to guide students in the development of English as a lingua franca. To successfully support additive multilingualism, EFL teachers need to implement adequate pedagogies that foster a safe and supportive classroom environment and that integrate students' multilingual and multicultural identities. In this paper, we have suggested the following teaching practices that promote such a classroom: welcoming diversity, funds of knowledge, clear goals, multimodality of input, opportunities for interaction, integrating language instruction with compelling content, facilitating multi-literacy, and differentiating instruction and assessment. We have based these suggestions in the current research in applied linguistic, bilingualism and multilingualism studies, and in our own classroom practices. Whereas we have not conducted experimental research to confirm the effectiveness of these guidelines and we do not claim that they constitute the ultimate answer to EFL teachers' daily classroom challenges, we hope that we 
have provided EFL teachers working with minority languages students with some useful tips they can explore in their next class.

References:

Baker, C. (1996). Foundations of Bilingual Education and Bilingualism. Clevedon: Multilingual Matters.

Beatens Beardsmore, H. (1979). Bilingual education for highly mobile children. Language Problems and Language Planning, 3, pp 138-155.

Beatens Beardsmore, H. (1890). Bilingual education in international schools. European schools and experimental schools: A comparative analysis. In Lim Kiat Boey (Ed.), Bilingual education (pp 3-19). Singapore: Singapore University Press.

Cenoz, J. \& Gorter, D. (2014). Focus on Multilingualism as an approach in Educational contexts. In Blackledge, A. \& Creese, A. (Eds.), Heteroglossia as practice and pedagogy. New York, London, Springer Dordrecht Heidelberg.

Cenoz, J., Hufeisen, B., \& Jessner, U. (2001). Towards trilingual education. International Journal of Bilingual Education and Bilingualism, 4(1), pp 1-10.

Coelho, E. (2004). Adding English: A guide to teaching multilingual classrooms. Toronto, ON, CAN: Pippin Publishing Corporation, 2004. ProQuest ebrary. Web. 24 October 2014.

Council of Europe (2011). Common European framework of reference for learning, teaching, assessment. Cambridge: Cambridge University Press.

Cummins, J. (2001). Instructional Conditions for Trilingual Development. International Journal of Bilingual Education and Bilingualism, 4(1), pp 61-75.

Cummins, J., Bismilla, V., Chow, P., Cohen, S., Giampapa, F., Leoni, L., Sandhu, P., \& Sastri, P. (2005). Affirming identity in multilingual classroom. Educational leadership, 63(1), pp 38-43.

Echevarría, J., Vogt, M. \& Short, D. (2008). Making Content Comprehensible for English Learners. The SIOP Model. Boston, New York: Pearson.

European Commission (2005). Communication from the Commission to the Council, the European Parliament, the European Economic and Social Committee and the Committee of the Regions: A New Framework Strategy for Multilingualism (COM 2005, 596 final). Retrieved on October 17, 2004, from http://eur-lex.europa.eu/legalcontent/EN/TXT/?uri=CELEX:52005DC0596.

Gonzalez, N., Moll, L., \& Amanti, C. (2005). Funds of knowledge: Theorizing practices in households, communities and classrooms. Mahwah, NJ: Lawrence Erlbaum Associates.

Jessner, U. (2006). Linguistic awareness in multilinguals: English as a third language. Edinburgh: Edinburgh University Press.

Krashen, S. (1982). Principles and practice in second language acquisition. New York: Pergamon Press.

Krashen, S. (2003). Explorations in language acquisition and use. Portsmouth, NH: Heinemann.

Krashen, S. (2005). Free Voluntary reading: New Research, Applications, and Controversies. In G. Poedjosoedarmo (Ed.) Innovative Approaches to Reading \& Writing Instruction. Republic of Singapore: SEAMEO Regional Language Centre, Anthology Series 46, pp $1-9$.

Krashen, S. (2013). Second language acquisition. Theory, applications, and some conjectures. Cambridge, New York: Cambridge University Press. 
Lambert, W. E. (1974). Culture and language as factors in learning and education. In F. E. Aboud \& R. D. Meade (Eds.), Cultural factors in learning and education, pp 91-122. Bellingham: Western Washington State College.

Lindahl, K. \& Watkins, N. (2014). What's on the 'LO' Menu? Supporting academic language objective development. The Clearing House: A Journal of Educational Strategies, Issues and Ideas, 87(5), pp 197-203.

Long, M. (1996). The role of the linguistic environment in second language acquisition. In Ritchie, W. \& Bhatia, T. Handbook of second language acquisition. San Diego: Academic Press, pp 413-468.

López-Gopar, M. E., Jiménez Morales, N., Delgado Jiménez, A. (2014). Critical classroom practices: Using "English" to foster minoritized languages and cultures in Oaxaca, Mexico. In Gorter, D., Zenotz, V., \& Cenoz, J. (Eds.), Minority languages and multilingual education. Bridging the local and the global. New York, London: Springer Dordrecht Heidelberg.

New Levine, L. \& McCloskey, M. L. (2013). Teaching English language and content in mainstream classes. One class, many paths $\left(2^{\text {nd }}\right.$ ed.). Boston, MA: Pearson.

O’Malley, J. M. and Valdez Pierce, L. (1996). Authentic assessment for English language learners. Practical approaches for teachers. New York: Addison-Wesley

Sagasta Errasti, M.P. (2003). Acquiring writing skills in a third language: The positive effects of bilingualism. International Journal of Bilingualism, 7(1), pp 27-42.

Schwarzer, D., Haywood, A., \& Lorenzen, C. (2003). Fostering multiliteracy in a linguistically diverse classroom. Language Arts, 80(6), pp 453-460.

Stille, S. \& Cummins, J. (2013). Foundation for learning: Engaging plurilingual students' linguistic repertoires in the elementary classroom. TESOL Quarterly, 47(3), pp 630-638.

Swain, M., Lapkin, S., Rowen, N., \& Hart, D. (1990). The role of mother tongue literacy in third language learning. Language, Culture and Curriculum, 3(1), 65-81.

Utdanningsdirektoratet (2006). Laereplanverket for Kunnskapslфftet (LK06). http://www.udir.no/Lareplaner/ Downloaded February, 2015. 